\title{
$\mathrm{ZrO}_{2}(2 \mathrm{Y}) / \mathrm{MoSi}_{2}$ 系複合体を積層した材料の電気的および機械的特性
}

\author{
村岡 芳幸, 吉川 文人, 廣田健, 山口修 \\ 同志社大学工学部, $\overline{\mathbf{T}} 610-03$ 京都府経喜郡田辺町.
}

\section{Electrical and Mechanical Properties of Three-Layer Laminated Materials Composed of $\mathrm{ZrO}_{2}(2 \mathrm{Y}) / \mathrm{MoSi}_{2}$ Composites}

\author{
Yoshiyuki Muraoka, Fumihito Yoshikawa, Ken Hirota and Osamu Yamaguchi \\ Faculty of Engineering, Doshisha University, Tanabe-cho, Kyoto 610-03.
}

Received July 31, 1995

\begin{abstract}
SYNOPSIS
Dense sintered materials ( $>99 \%$ of theoretical) consisting of three-layer structures with the compositions of $\mathrm{ZrO} 2(2 \mathrm{Y}) / \mathrm{MoSi} 2$ $=(60 / 40: A) /(80 / 20: B) /(60 / 40: A)$ molo have been able to be fabricated by hot isostatic pressing at $1400^{\circ} \mathrm{C}$ for $2 \mathrm{~h}$ under 196 MPa. The materials show an anisotropy in overall electric resistivities measured in the perpendicular and parallel directions for the laminated interfaces: the former and latter resistivities correspond to insulating $\left(\rho_{\perp} \approx 1 \times 10^{11} \Omega \cdot \mathrm{cm}\right)$ and metallic $\left(\rho_{r} \approx 1 \times 10^{-4} \Omega \cdot \mathrm{cm}\right)$ materials, respectively. The fracture toughness ( $K I c)$ is much affected by the residual stress estimated to be as much as $\approx 150 \mathrm{MPa}$ at the interfaces. The residual stress acts as compressive and tensile stresses in the layers $A$ and $B$, respectively.
\end{abstract}

KEY WORDS

$\mathrm{ZrO}_{2}(2 \mathrm{Y})-\mathrm{MoSi}$ system, laminated material

\section{1 緒言}

高温度下で使用可能な構造用材料であるケ イ化モリブデン $(\mathrm{MoSi} 2)$ は, 耐酸化性, 耐食性 および高融点 $\left(2030^{\circ} \mathrm{C}\right)$ といった優れた特徵 を有しているが，他の多くの金属間化合物と 同様, 破壊勒性值KIcが小さいという久点があ る.

本研究者等は, 先にMoSi2に2モル\%のイッ トリア $\left(\mathrm{Y}_{2} \mathrm{O}_{3}\right)$ を含むジルコニア $\left(\mathrm{ZrO}_{2}\right)$ を添加 した複合体を作製し特性を評価したところ, $\mathrm{ZrO}_{2}$ 準安定正方晶相として均一に分散させ
ることにより，機械的特性が大幅に向上する ことを報告1)した.さらに $\mathrm{ZrO}_{2}(2 \mathrm{Y})$ リッチ組 成の複合体において，Fig. 1 に示すように $\mathrm{ZrO}_{2}(2 \mathrm{Y}) / \mathrm{MoSi} 2=60 / 40$ モル\%から 80/20モル $\%$ 組成の間で, 電気抵抗率が低抵抗(金属 性)から高抵抗(絶縁性)まで急激に変化するこ とを見い出した.

一方, 複合体の組成を傾斜させ新しい機能 や特性を発現させる試みが近年活発に行われ ており， $\mathrm{ZrO}_{2}$ と金属 $(\mathrm{Ni}, \mathrm{SUS}$ 等)を用いた多 層構造の傾斜機能材料や，その基本となる積 




Fig.1 Electric resistivity of $\mathrm{ZrO}_{2}\left(2 \mathrm{~mol}_{\mathrm{g}} \mathrm{Y}_{2} \mathrm{O}_{3}\right) / \mathrm{MOSi} 2$ composites as a function of $\mathrm{ZrO}_{2}(2 \mathrm{Y})$ content.

層材料に関して多くの報告2)がなされている. しかし， $\mathrm{ZrO}_{2}$ と金属間化合物を組み合わせた 積層材料の作製やその特性に関する報告は見 あたらない，本研究では，金属性および絶緣 性の電気抵抗率を示す二種類の $\mathrm{ZrO}_{2}(2 \mathrm{Y}) /$ MoSi2系複合体を積首した材料を作製し，そ の電気的特性および機械的特性を, 微細構造 や積層界面に発生する残留応力と関連づけて 詊価した.

\section{2 実験方法}

2 モル\%のY ${ }_{2} \mathrm{O}_{3}$ を含む平均粒径 $0.023 \mu \mathrm{m}$ の $\mathrm{ZrO}_{2}$ 粉体 $\left(\mathrm{ZrO}_{2}(2 \mathrm{Y})\right.$ ，純度 $\left.99.99 \%\right)$ と平均粒


料として用いた。両粉体を $\mathrm{ZrO}_{2}(2 \mathrm{Y}) / \mathrm{MoSi} 2$ =60/40と 80/20モル\%組成（以後, 組成"A",

"B"と呼ぶ) に秤量し，ボールミルにて20h湿 式混合( $\mathrm{ZrO}_{2}$ ビーズ，エタノールを使用)した 後, $80^{\circ} \mathrm{C}$ で乾燥した，仮焼することなしに混 合粉体を金型内にてA/B/Aに積層後, $150 \mathrm{MPa}$ の圧力で一軸成形し，さらに392MPaの圧力で 冷間静水圧プレス(CIP)した. 成形体を窒化ホ ウ素(BN)粉体で被った後，パイレックスガラ スに真空封入しHIP焼結した. HIP焼結の条件 は以下のとおりである. (1)温度は室温から $600^{\circ} \mathrm{C}$ な゙1hで，そして600〜 $1400^{\circ} \mathrm{Cでは} 400$ ${ }^{\circ} \mathrm{C} / \mathrm{h}$ の速度で昇温した. (2)圧力は室温から

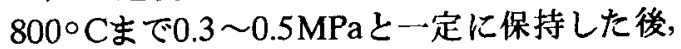
$800^{\circ} \mathrm{C}$ か約 $180 \mathrm{MPa} / \mathrm{h}$ の速度で昇圧した。 (3)196MPaの圧力下で $1400^{\circ} \mathrm{C} て ゙ 2 \mathrm{~h}$ 保持した後, 室温まで1 hで冷却した.

焼結体はダイヤモンドカッターで切断し，


鏡面に仕上げた後，X線回折によって相を同 定した。試料の嵩密度はアルキメデス法にて 湘定した。微細構造は走查型電子顕微鏡 (SEM)を用いて観察した. 鏡面仕上げした試 験片 $(\approx 3 \times 9 \times 20 \mathrm{~mm})$ を用いて，スパン長さ $16 \mathrm{~mm}$, クロスヘッドスピード $0.5 \mathrm{~mm} / \mathrm{min}$ の条件で曲 げ強度 $\sigma \mathrm{b}$ を測定した．また荷重196Nでビッカ 一不硬度 $H_{v}$ ，IF法により破壊勒性值 $K$ Ic を求め $た^{3)}$. 比較のためA，Bのみからなる単層複合 体についても同一条件で作製し，特性を評価 した.

\section{3 実験結果および考察}

\section{1 積層材料の密度と微細構造}

HIP烧結することにより, 直径 $24 \mathrm{~mm}$, 厚 さ $\approx 9 \mathrm{~mm}$ (各層の厚さ $\approx 3 \mathrm{~mm}$ )の緻密な積層材料 を作製することができた. Photograph 1に断 面の光学顥微鏡写真を示す，積層界面および 材料全体にクラックは観察されなかった.こ れは各単層および材料全体の強度が界面に発 生する残留応力よりむ大きいためである。こ の点については後で詳しく述べる.

$\mathrm{X}$ 線回折 $(\mathrm{Cu} K a$ 線, Niフィルター)により, $\mathrm{ZrO}_{2}(2 \mathrm{Y})$ の正方晶ジルコニア $\left(t-\mathrm{ZrO}_{2}\right)$ と単斜 晶ジルコニア $\left(m-\mathrm{ZrO}_{2}\right)$ の体積比率 $(t / m \text { 比率 })^{4)}$ を調べた. 出発原料の粉体の $t / m$ 比率は45/55 \%であったが，積層材料中のZrO2はすべて $\mathrm{t}$ $\mathrm{ZrO}_{2}$ であり， $m-\mathrm{ZrO}_{2}$ 相は認められなかった。 この理由は, 積層材料中のZrO2の結晶粒径が 小さく, かつ $\mathrm{ZrO}_{2}$ と $\mathrm{MoSi} 2$ のポアッソン比 $\left.\left(\mu\left(\mathrm{ZrO}_{2}\right)=0.25^{5}\right), \mu(\mathrm{MoS} \dot{\mathrm{z}})=0.15^{6}\right)$ が異なる ためにZ $\mathrm{Zr}_{2}$ 粒子の周囲に応力が発生し, 高温 相のt-Z $\mathrm{rO}_{2}$ が室温まで保持されたためと考え られる。また MoSi2 リッチ組成のMoSi2/ZrO2 系複合体 ${ }^{1)}$ と同様, $\mathrm{ZrO} 2$ と $\mathrm{MoSi}_{2}$ 以外の結晶 相は認められなかった。

積層材料の蒿密度は $6.10 \mathrm{~g} / \mathrm{cm}^{3}$ であり, $t$ $\mathrm{ZrO}_{2}(2 \mathrm{Y}) ， \mathrm{MoSi} 2$ 理論密度をそれぞれ $\left.6.085 \mathrm{~g} / \mathrm{cm}^{3} 7\right), 6.27 \mathrm{~g} / \mathrm{cm}^{3}$ 8) として算出した相 対密度は99.9\%であった.MoSi2リッ千組成の 


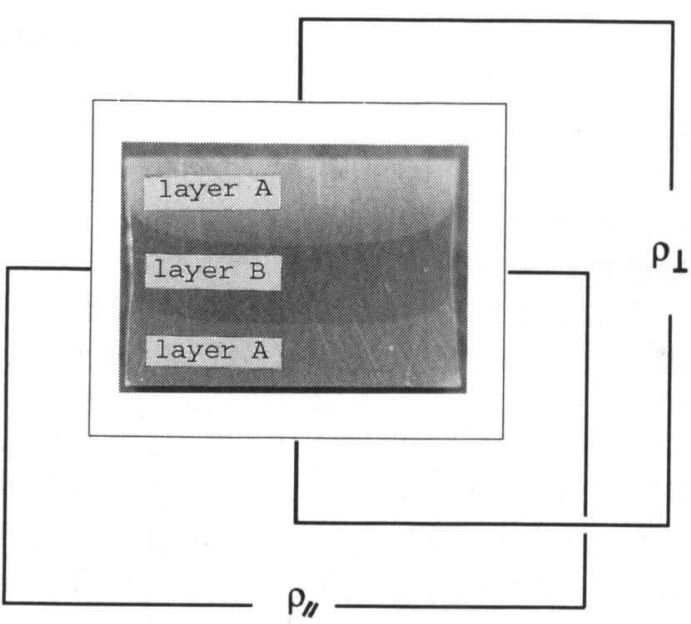

Photo.1 Optical photograph for cross section of laminated material.

複合体の相対密度(97.1-99.0\%) ${ }^{1)}$ よりも高密度 の焼結体が得られたのは易焼結性である $\mathrm{ZrO}_{2}(2 \mathrm{Y})$ 成分の増加に起因している.

Photograph 2の(a)はA層，(b)はB層の微細 構造を示す。緻密な組織の中に微小粒径の $\mathrm{ZrO}_{2}(2 \mathrm{Y})$ と大きな粒径をもつ $\mathrm{MoSi}_{2}$ が均一に 分布していることがわかる. $\mathrm{ZrO}_{2}(2 \mathrm{Y})$ と $\mathrm{MoSi}{ }_{2}$ それ゙れの平均結晶粒径はA層では 0.23 と $1.8 \mu \mathrm{m}$ であり, B層では 0.23 と $1.2 \mu \mathrm{m}$ であっ た.

\section{2 積層材料の電気的特性}

電気抵抗率を積層界面に対して垂直方向・ $\left(\rho_{\perp}\right)$ および平行方向 $\left(\rho_{\|}\right)$に測定すると (Photo. $1), \rho_{\perp} \approx 1 \times 10^{11}$ と $\rho_{\|} \approx 1 \times 10^{-4} \Omega \cdot \mathrm{cm}$ の值が得られ た.この結果を複合体の電気抵抗に関する"実 効媒質理論(General Effective Media: GEM) ${ }^{9}$ )" に基づいて考察した．主要な構成要素が絶縁 性物質で, 副成分要素が高導電性物質からな る複合体の電気抵抗率は[1]式で表わされる.

$$
\rho_{\mathrm{m}}=\rho_{\mathrm{h}}(1-\phi)^{3}
$$

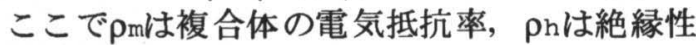
物質の電気抵抗率, $\phi$ は高導電性物質の体積率 である. $\rho \mathrm{h}$ とて $\mathrm{ZrO}_{2}(2 \mathrm{Y})$ の電気抵抗率 $\approx 10^{12} \Omega \cdot \mathrm{cm}^{10)} ， \phi$ として20モル\% $\mathrm{MoSi}_{2}$ の 体積率 0.231 [1]式に代入することにより， B 層の電気抵抗率 $\rho B: G E M \approx 4.6 \times 10^{11} \Omega \cdot \mathrm{cm}$ が得られ た. 一方, 主要な構成要素が高導電性物質で, 副成分要素が絶縁性物質からなる複合体の電 気抵抗率は[2]式で表わされる.

$$
\rho_{\mathrm{m}^{*}}=1 /\left\{\sigma_{\mathrm{h}}(1-f)^{2 / 3}\right\}
$$
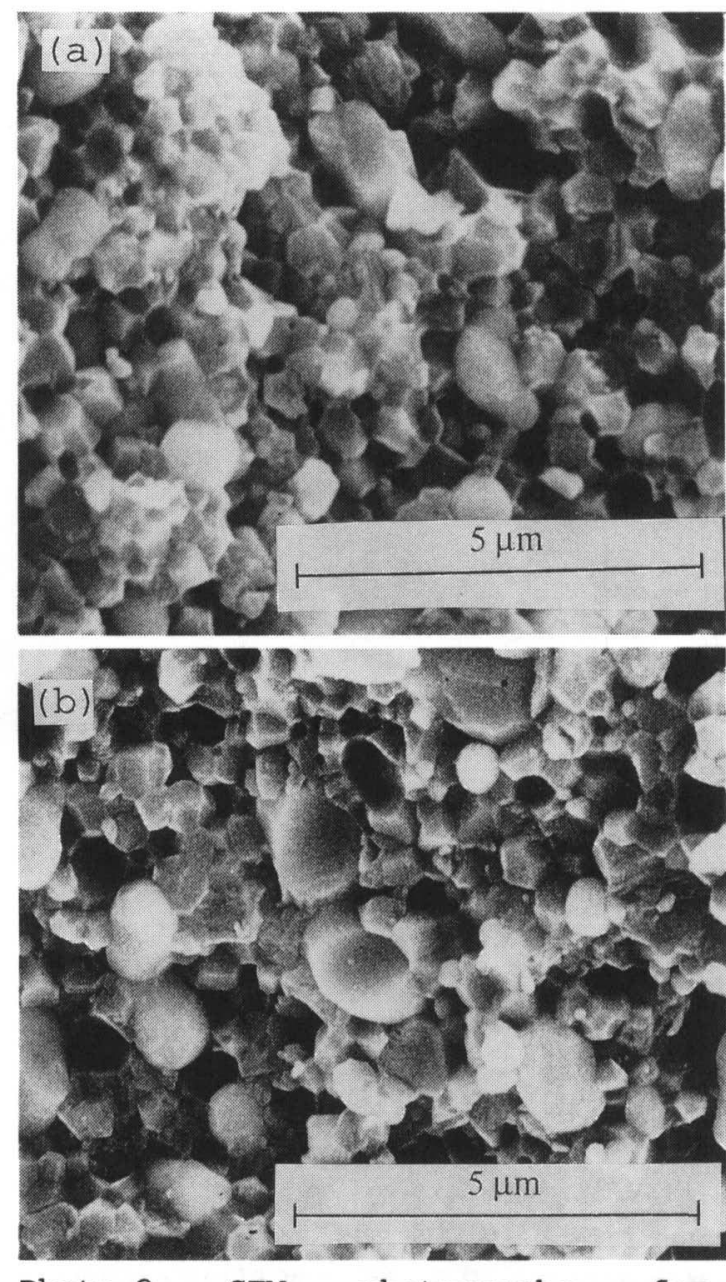

Photo.2 SEM photographs for fracture surfaces of (a) layer A and (b) layer $B$ in laminated material.

ここで $\rho_{\mathrm{m}} \star$ は複合体の電気抵抗率， $\sigma_{\mathrm{h}}$ は高導電 性物質の電気伝導率, fは絶縁性物質の体積率 である。 $\sigma_{\mathrm{h}}$ として $\mathrm{MoS}$ i2 の電気伝導率 $\left.\approx 4.65 \times 10^{4} \mathrm{~S} \cdot \mathrm{cm}^{-1}{ }^{8}\right), f$ として 60 モル \% $\mathrm{ZrO}_{2}(2 \mathrm{Y})$ の体積率 0.555 を[2]式に代入し，複 合体Aの電気抵抗率 $P A$ : $G E M=0.72 \times 10^{-4} \Omega \cdot \mathrm{cm}$ を算 出した. $\rho_{A}: G E M \approx 0.72 \times 10^{-4} \Omega \cdot \mathrm{Cm}$ と $\rho \mathrm{B}: \mathrm{GEM} \approx 4.6 \times 10^{11} \Omega \cdot \mathrm{cm}$ の值を用いて, 積層界面 に垂直方向と平行方向の電気抵抗率を求める と $\rho \perp:$ GEM $1.56 \times 10^{11}$ と $\rho "$ :GEM $1.08 \times 10^{-4} \Omega \cdot \mathrm{Cm}$ が 得られ, 実測値とよく一致した.

\section{3 積層材料の機械的特性}

Figure 2に破壊勒性値KIcの分布を示す．界 面に平行な方向にクラックが発生するように ビッカース圧痕を形成させて，その大きさと クラックの長さから評価した $K \mathrm{Ic} の$ 值は, 界面 




Fig.2 Fracture toughness of laminated material: $(O)$ parallel and (O) perpendicular directions for interfaces. Symbols (D) and (O) show the values of monolythic composites $A$ and $B$, respectively.

に接近するにつれて $\mathrm{A}$ 層では 6.3 から $4.6 \mathrm{MPa} \cdot \mathrm{m}^{1 / 2}$ に減少し, $\mathrm{B}$ 層では逆に8.3から $8.9 \mathrm{MPa} \cdot \mathrm{m}^{1 / 2}$ に增加した．一方，界面と垂直方 向で測定したKIcの值は，前述の平行方向に測 定した KIcの値と反対の傾向を示した。 すなわ ち, A層ではKIcの值は界面に接近するにした がって6.6から $8.2 \mathrm{MPa} \cdot \mathrm{m}^{1 / 2}$ に増加し，B層では 逆に7.0から6.1MPa・再1/2に減少した。比較の ため単層複合体AおよびBのKIcの值を測定す るとそれぞれ6.7および7.8MPa・ $\mathrm{m}^{1 / 2}$ であり, これらの值は積層材料の各層の中央付近にお けるKIcの值に対応している.ここで测定方法 や测定箇所に依存するKIcの值の変化は，残留 応力が積層界面付近に存在していることを示 唆している.そこで[3]式11)を用いて界面近傍 での応力の值を算出した.

$$
\tau_{R}=(\sqrt{\pi} / 2)\left(K^{\mathrm{O}_{\mathrm{Ic}}}-K_{\mathrm{Ic}}\right) / \sqrt{c}
$$

ここで $\tau_{R}$ は残留応力, $K^{\circ}$ Icは応力のない場合 における自由表面での破壊勒性值，KIc とcは 応力の存在する場合の破壊勒性值とクラック の長さである. $\tau_{R}$ として150MPaの值*が得られ た.

次に界面に垂直な方向にクラックが発生す るようにビッカース压痕を形成させ，クラッ クを光学顥微鏡で観察した. クラックの伸張
は压縮応力の存在下では抑制されるのに対し て，引つ張り応力下では促進される．B層にお けるクラックの方がA層のそれよりむ短かか ったことから, 残留応力はA層では压縮応力, B層では引っ張り応力として作用していること が確認された。

一方, 荷重方向が界面に平行になるように 测定した積層材料の曲げ強度 $\sigma$ bは1020MPaで あり，残留応力よりも積層材料全体の強度が 大きいことを示した．比較のため単層複合体 の $\sigma$ bを湘定すると，A組成の複合体では $1150 \mathrm{MPa} ， \mathrm{~B}$ 組成の複合体では1210MPaであり， 積層材料の $\sigma$ bは，単相複合体のそれより 100 200MPa低い值であった.

A凰およびB層の熱膨張係数の差から, 積層材料の界面 に垂直な断面における熱底力を概算すると $\approx 70 \mathrm{MPa} の$ 值 を得た. この值は, ビッカース压痕から求めた界面近 傍における残留応力 $\left(\tau_{R \approx 150 \mathrm{MPa}}\right)$ を界面に垂直な断面 で単純平均化した值 ( $75 \mathrm{MPa})$ とほぼ一致する，概算に 当たっては, $\mathrm{ZrO} 2(2 \mathrm{Y})$ と $\mathrm{MoSi} 2$ の体積弾性率 $\left.(K(\mathrm{ZrO} 2(2 \mathrm{Y}))=138.0 \mathrm{GPa}, K(\mathrm{MoSi} 2)=210.5 \mathrm{GPa})^{12,13}\right)$, $\mathrm{A} お$ よび $\mathrm{B}$ 層の線膨張係数 $\left(\alpha \mathrm{A}=9.305 \times 10^{-6} / \mathrm{K}\right.$, $\left.\left.\alpha \mathrm{B}=9.7758 \times 10^{-6} / \mathrm{K}\right)^{14}\right)$ と弾性率 $(E \mathrm{~A}=311.6 \mathrm{GPa}$ と $E B=261.3 \mathrm{GPa})^{15)}$ の值を用いた. 


$$
4 \text { まとめ }
$$

部分安定化ジルコニアZrO2(2Y)と金属間化 合物のMoSi2を用いて, 各層の組成が $\mathrm{ZrO} 2(2 \mathrm{Y}) / \mathrm{MoSi} 2=(60 / 40) /(80 / 20) /(60 / 40)$ モル $\%$ 組成である緻密な積層材料を, HIP 焼結 (1400C-2h-196MPa)により作製することがで きた. 積層材料の電気的および機械的特性に ついて評価したところ，以下の結論が得られ た.

i) 積層界面に対して平行方向に電気抵抗率を 湘定すると金属性 $\left(\rho_{\prime \prime} \approx 1 \times 10^{-4} \Omega \cdot \mathrm{cm}\right)$ であり, 垂直方向では絶緣性 $\left(\rho_{\perp} \approx 1 \times 10^{11} \Omega \cdot \mathrm{cm}\right)$ であ る.

ii）界面近傍における残留応力により, 破壞靬 性值の分布に異方性が認められた。

iii)残留応力の大きさは, ビッカース在痕のク ラック長さと破填靶性值から算出すると界 面近傍で $150 \mathrm{MPa}$ である.

iv)残留応力はA層では圧縮応力, B層では引っ 張り応力として作用する。

\section{謝辞}

本研究は, 徳山科学技術振興財団の助成を 受けた．記して謝意を表します。

\section{文献}

1) T.Yamada, K.Hirota, and 0 . Yamaguchi: Mat. Res. Bull., in press.

2) 例えば, Y.Itoh and H.Kashiwaya: J.Ceram.Soc.Jpn . , 100 [4] (1992) 476, 小崎亮, 渡辺龍三：粉体および粉末
治金，37，（1990） 250.

3) K. Niihara, N. Nakahira, and $T$. Hirai: J.Am.Ceram.SoC., 67 (1984) C-13.

$4)$ H. Toraya, M. Yoshimura, and $S$. Somiya : J. Am.Ceram. SoC. , 55(1972) 303.

5) F.F.Lange: J.Mater.Sci., 17 (1982) 247.

6) M.Nakamura, S.Matsumoto, and $T$. Hirano: J.Mater, SCi., 25 (1990) 330.

7) R.P.Ingel and D.Lewis III: J.Am. Ceram.Soc. ,25(1986)3309.

8) 堂山昌男, 矢部正也 : 金属間化合物ハン ドブック，サイェンスフォーラム (1989) 104-105.

9) D. S.McLachlan, M.Blaszkiewicz, and R.E.Newnham:J.Am.Ceram.SoC., 73 (1986) 2187.

10) 奥田博, 平井敏雄, 上垣外修已 : 構造用 セラミックス, オーム社 (1987) 134.

11) D.B.Marshall and B.R.Lawn:J.Am. Ceram.Soc. , 60[1-2] (1977)87.

12) H. Schubert: J.Am. Ceram. SoC. , 69 (1986) 270 .

13) A. K. Bhattacharya and J. J. Petrovic: J.Am.Ceram.SoC.,75 (1992) 23.

14) Turner: J.Res.NBS., 37 (1946) 239.

15) W.D.Kingery, H.K.Bowen, and D.R. Uhlmann: Introduction to Ceramics (Second Edition), John Wiley \& Sons, New York (1976) 774,817. 